\title{
THE EFFECT OF MYCORRHIZAL SYMBIOSIS AND SEED PRIMING ON THE AMOUNT OF CHLOROPHYLL INDEX AND ABSORPTION OF NUTRIENTS UNDER DROUGHT STRESS IN SESAME PLANT UNDER FIELD CONDITIONS
}

\author{
ASKARI, A. ${ }^{1,2^{*}}-$ ARDAKANI, M. R. ${ }^{3}-$ VAZAN, S. $^{3}-$ PAKNEJAD, F. ${ }^{3}-$ HoSSEINI, Y. ${ }^{4}$ \\ ${ }^{1}$ Islamic Azad University, Karaj Brach, Karaj, Iran \\ ${ }^{2}$ Seed and Plant Improvement Research Department, Hormozgan Agricultural and Natural \\ Resources Research and Education Center, Agricultural Research, Education and Extension \\ Organization (AREEO), Bandar Abbas, Iran \\ ${ }^{3}$ Islamic Azad University, Karaj Brach, Karaj, Iran \\ ${ }^{4}$ Soil and Water Research Department, Hormozgan Agricultural and Natural Resources \\ Research and Education Center, Agricultural Research, Education and Extension Organization \\ (AREEO), Bandar Abbas, Iran \\ *Corresponding author \\ e-mail: Ahaskari2005@gmail.com; phone:+98-913-345-3732 \\ (Received $7^{\text {th }}$ Jul 2017; accepted $4^{\text {th }}$ Dec 2017)
}

\begin{abstract}
Plants are exposed to environmental stresses during their growth. One of the most important stresses is drought stress, which can affect the absorption and transfer of nutrients to the plant. The use of advantageous microorganisms such as mycorrhizal fungi as well as seed priming are among the solutions that have been taken into consideration in many plants in recent years to mitigate the effects of water shortages and drought stress. In the present study, the effect of mycorrhizal symbiosis and seed priming on the amount of chlorophyll index and absorption of nutrients in sesame oilseed under drought stress was investigated during 2013 and 2014 at the farm of Hajiabad Agricultural Research Station in Hormozgan- Iran. The main drought stress factor included irrigation based on providing $100 \%$ of the plant's water requirement (normal irrigation), providing $70 \%$ of the plant's water requirement (mild stress) and providing $50 \%$ of the plant's water requirement (severe stress), Priming substrate was at three levels: no priming (control), hydro-priming and osmo-priming, and another sub-factor consisted of mycorrhiza fungi species: without inoculation mycorrhizal fungi (control), using Glomus mosseae and Glomus intraradices. The results of combined analysis of variance showed that the effects of drought stress and mycorrhizal symbiosis on leaf chlorophyll index, nitrogen $(\mathrm{N})$, phosphorus $(\mathrm{P})$, potassium $(\mathrm{K})$, iron $(\mathrm{Fe})$, zinc $(\mathrm{Zn})$ and copper concentration $(\mathrm{Cu})$ in leaf were significant. Sodium concentration was only significantly affected by drought stress and seed priming was only effective on $\mathrm{Cu}$ concentration. Interaction of irrigation $\times$ mycorrhizal symbiosis was significant on pand $\mathrm{Cu}$ uptake and interaction of irrigation $\times$ seed priming was only significant on iron concentration. Results showed that severe drought stress (providing 50\% of plant water requirement) had the highest effect on decreasing amount of chlorophyll index and concentration of nitrogen and phosphorus elements in leaves, whereas concentrations of potassium, zinc, iron, copper and sodium increased with drought stress. Inoculation with mycorrhizal fungi increased the amount of chlorophyll index, nitrogen, phosphorus, potassium, zinc, iron and copper uptake compared with the absence of mycorrhizal fungi.
\end{abstract}

Keywords: chlorophyll index, drought stress, mycorrhizal symbiosis, nutrients, seed priming, sesame 


\section{Introduction}

Sesame (Sesamum indicum L.) is an annual and diploid that grows strong. Direct sesame root system, which is capable of robust and wide-permeable soils, warm and moist to a depth of $2 \mathrm{~m}$ to penetrate. Depth development of roots in irrigated conditions is often less than $1 \mathrm{~m}$, with the majority of the roots to a depth of $60 \mathrm{~cm}$ can be seen. Drought is one of the most common abiotic environmental stresses and the most important limiting factor for a successful crop producing, especially in arid and semiarid regions of the world (Kramer and Boyer, 1995). One of the most harmful effects of drought stress is disruption in the process, absorption and accumulation of nutrients that causes the reduction of grain and forage yield (Irannejad, 1991). Drought stress decreased total and b chlorophyll and leaf RWC in various Sesame genotypes (Hassanzadeh et al., 2009). The plant can withstand drought through various mechanisms, such as closing the stomata, thickening of the cuticle, reducing transpiration, preventing protein depletion and osmotic regulation (Premachandra et al., 2002). The mechanisms of absorption and transfer of nutrients in plants, such as mass flow, emission or absorption and transfer by osmotic phenomena, are all function of the moisture content of the soil and the expansion of the absorbing root, and in the case of reduced moisture or roots expansion, intensity and amount of nutrient uptake are undergoing changes (Taiz and Ezeiger, 1998). Sesame plants are adversely affected by continuous flooding conditions or environments severe drought (Menshah et al., 2006). Various approaches have been proposed to mitigate the effects of drought soils, such as disruption in nutrient uptake and reduction of chlorophyll content of leaves. Biological solutions, such as the use of microorganisms, like mycorrhiza fungi, are solutions that have recently attracted more attention. Application of Glomus spp. (VA mycorrhizae) significantly reduced wilt and root-rot incidence of sesame plants. Lums spp. (VA mycorrhizae) also significantly increased plant morphological characters such as plant height, number of branches and number of pods for each plant. Using Glomus spp. to protect sesame plants by colonizing the root system, significantly reduced colonization of fungal pathogens in sesame rhizosphere as well as pathogenic activity of fungal pathogens increased lignin contents in the sesame root system were also observed. Furthermore, mycorrhizae treatment provided selective bacterial stimulation for colonization on sesame rhizosphere. These bacteria belonging the Bacillus group showed highly antagonistic potential to fungal pathogens (Ziedan et al., 2011). Both mixed biofertilizer of Pseudomonas geniculate and Alcaligenes faecalis and foliar application of $\mathrm{KCl}$ had significant positive effect on the sesame yield, oil content and chemical constituents of sesame seeds under saline condition (Omer and Abd-Elnaby, 2017). Arbuscular mycorrhizal fungi play an important role in improving the nutrition and growth of plants under drought conditions (Singh et al., 1997). Mycorrhiza fungi, as one of the most important microorganisms in the soil, by coexistence with many plant species, improve the absorption of water and nutrients by host plants (Smith and Read, 1997). Today it is known that mycorrhizal fungi increase the nutrition of plants and, consequently, increase the growth of host plants by enhancing the absorption of nutrients and water (Feng et al., 2002). Studies show that mycorrhizal fungi contribute to plant growth under drought stress by increasing nutrients absorption and reducing stress (Ruiz-lozano and Azcon, 1996). Increasing the absorption of mineral elements, especially non-moving elements such as phosphorus in the host plant, is the most important effect of the symbiotic relationship with mycorrhizal fungi (Li et al., 1991; Bolan, 1991). The mycorrhiza inoculation could help in effective utilization of rock 
phosphate by changing it into available forms, which is later taken up by the sesamum plant for their better growth and development. The AM symbiosis optimized the Phosphorus solubilization from Rock Phosphate and affects microbial activity in the hyphosphere of Sesamum indicum L., oil yielding plants (Sabannavar and Lakshman, 2009). Mycorrhiza fungi hyphae can enter into very small pores that even root hairs cannot penetrate into them and cause more water absorption (Tisdall, 1991). Mycorrhizal inoculation significantly increased sesame root colonization under both sterile and nonsterile soil conditions compared to the control. Mycorrhizal inoculation significantly improved nutrient uptake of sesame particularly $\mathrm{N}, \mathrm{P}, \mathrm{K}, \mathrm{Ca}, \mathrm{Mg}, \mathrm{Na}, \mathrm{Fe}$, $\mathrm{Cu}, \mathrm{Mn}$ and $\mathrm{Zn}$ under both sterile and non-sterile soil conditions (Babajide and Fagbola, 2014). The indigenous AMF improved the growth and yield characters of sesame though their efficiency varied (Harikumar, 2013). Application of mycorrhizal fungi significantly increases leaf number and leaf area of Sesamum. The leaf area increased by $136 \%$ at the plants inoculated with Glomus fasciculatum and number of leaves by $70 \%$ at the plants inoculated with Glomus mosseae. Moreover, inoculation improved the root system by increasing volume and dry weight of roots (Boureima et al., 2007). Inoculation with mycorrhiza showed more efficiency, and were positively reflected in growth traits (plant height, leaf number, dry weight, tissue phosphorus and nitrogen) than addition of mineral phosphorus (Alsamowal et al., 2016). It is indicated that the reason for reducing the absorption of sodium, phosphorus and potassium from plant roots in dry soil is lower access of plants to these elements availability (Fatemy and Evans, 1986). Due to the fact that the absorption of nutrients changes with irrigation regimes, these changes affect the growth and yield of the plant, as well as the fact that mycorrhizal fungi have symbiotic relationship with the roots of most crops and with increasing water absorption, nutrient elements and resistance to environmental stresses cause growth and development of host plant. According to recent drought in Hajiabad region as well as relative resistance of Sesame against drought stress, the aim of this study was:

1. Evaluation the effects of mycorrhizal symbiosis on sesame oilseed

2. The effect of seed priming on sesame oilseed

3. The effect of drought stress on sesame oilseed in Hormozgan region.

\section{Materials and methods}

In order to evaluate the effects of mycorrhizal symbiosis, seed priming and drought stress on chlorophyll index and nutrient absorption, a split factorial based on randomized complete block design with 3 replications was carried out in Agricultural Research Station of Hajiabad county, Hormozgan province, during 2014 and 2015. The longitude of the experiment site was $55^{\circ} 54^{\prime}$ and its latitude was $28^{\circ} 19^{\prime}$, and the altitude is $920 \mathrm{~m}$ (Fig. 1), the mean annual precipitation and evaporation were 262.7 and $3200 \mathrm{~mm}$, respectively, and climate is among warm and dry areas (Figs. 4 and 5). Some characteristics of the physical and chemical properties of the soil are presented in Table 1.

Table 1. Physico-chemical soil properties of the experimental site

\begin{tabular}{c|c|c|c|c|c|c|c}
\hline Year & $\begin{array}{c}\text { Soil depth } \\
(\mathbf{c m})\end{array}$ & Texture & $\begin{array}{c}\text { EC } \\
(\mathbf{d s} / \mathbf{m})\end{array}$ & $\mathbf{p H}$ & $\begin{array}{c}\text { Organic } \\
\text { carbon }(\boldsymbol{\%})\end{array}$ & $\begin{array}{c}\text { Available P } \\
(\mathbf{m g} / \mathbf{l})\end{array}$ & $\begin{array}{c}\text { Available K } \\
(\mathbf{m g} / \mathbf{l})\end{array}$ \\
\hline 2014 & $0-30$ & Sandy-loamy & 2.43 & 8.01 & 0.63 & 6.3 & 185 \\
2015 & $0-30$ & Sandy-loamy & 2.22 & 7.98 & 0.77 & 5.9 & 203 \\
\hline
\end{tabular}




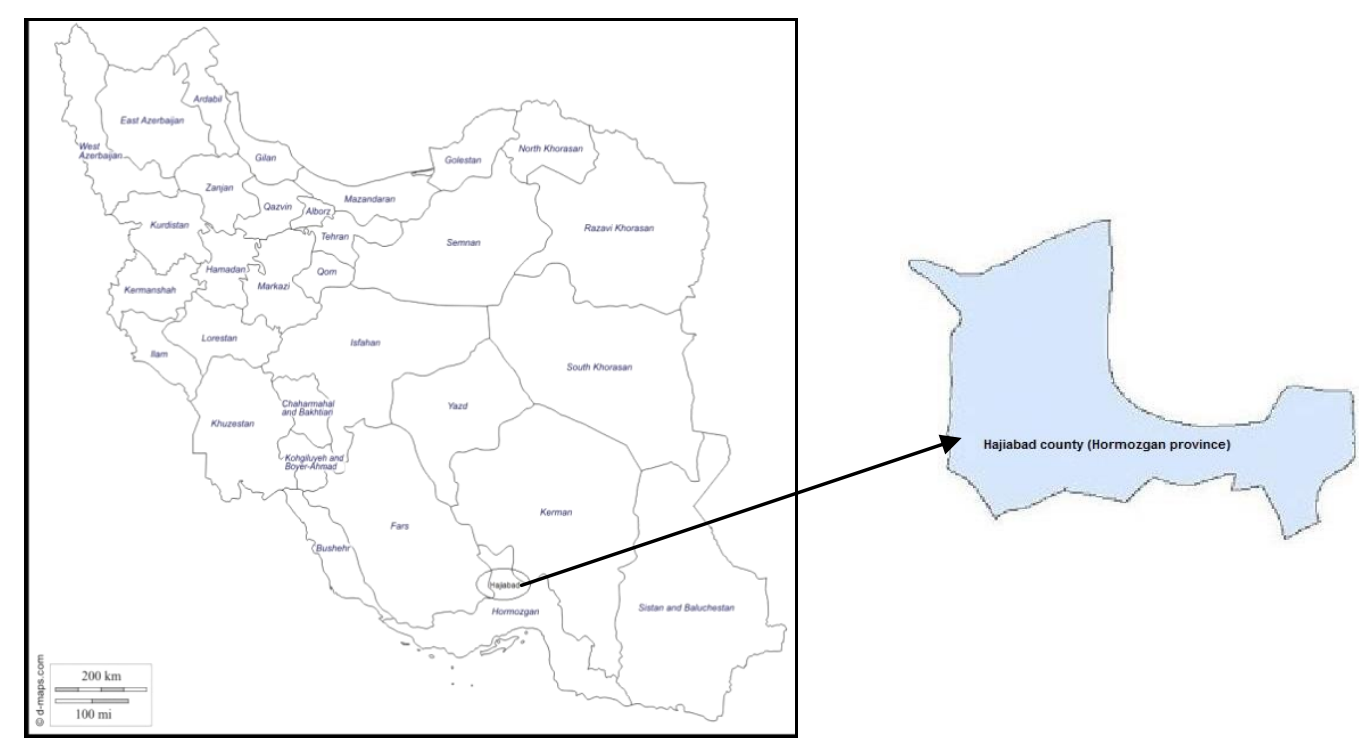

Figure 1. Location of the experiment site within Iran

The main plot of drought stress (Fig. 2) were as following: irrigation based on $100 \%$ water requirement (normal irrigation), providing $70 \%$ of the plant's water requirement (mild stress) and providing 50\% of the plant's water requirement (severe stress) and sub plots of seed priming experiments were designed at three levels: no priming (control), hydro priming ( $24 \mathrm{~h}$ in distilled water and then air dried $24 \mathrm{~h}$ ) and osmo-priming (using a solution of PEG 6000, 0.2 MPa and Placing seeds in a solution for $24 \mathrm{~h}$ and then air dry them for $24 \mathrm{~h}$ and another sub-treatments included different species of mycorrhizal fungi: Without incubation mycorrhiza fungi (control), incubation with $G$. mosseae and G. Intraradices species.

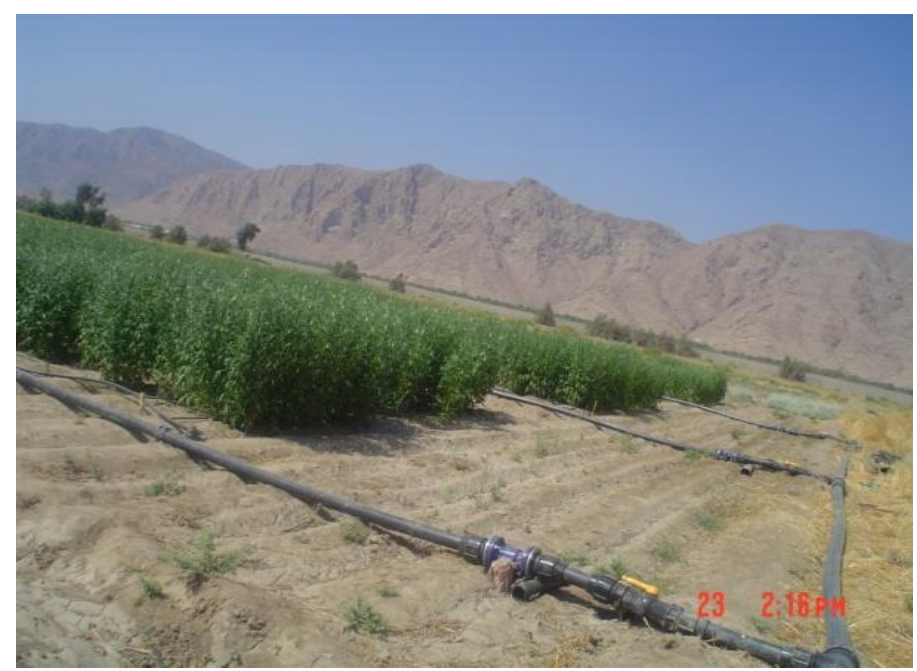

Figure 2. Irrigation of drought stress treatments in sesame experiment site

The used Mycorrhizal inoculum that was obtained from corn which planted in pot involved tiny pieces of symbiosis corn roots, contained hyphae, vesicles, arbuscular and fungal spores and soil with them. Seedbed preparation included plowing, disking and 
leveling in June and planting operations were performed in the first half of July for two years of experiment. Each plot consisted of 6 lines with a length of $5 \mathrm{~m}$ and a row spacing of $40 \mathrm{~cm}$ and $10 \mathrm{~cm}$ plant spacing on a row. In order to prevent mixing treatments effects, the sub-treatment space from each other was $1.5 \mathrm{~m}$ and the main treatments were $2 \mathrm{~m}$ and the space between repetitions was $3 \mathrm{~m}$. At 2-3 leaf stage and complete plant development, all treatments were irrigated uniformly and after this stage, different levels of drought stresses were applied. To determine the amount of irrigation at desired level of irrigation, the results of the research about the determination of water requirement of the Guam reference plant (ETo) in the Hajiabad region that was determined by (Moradi-Dalini, 2012) and the amount of plant coefficient (Kc) of sesame at different stages of growth from the results Published by the National Institute of Soil and Water Research were used (Farshi et al., 1998). Finally, considering the effective rainfall, the amount of water for irrigation of sesame was calculated for complete irrigation (without stress) and according to that amount, the water used in each level of drought stress was calculated. These calculated values with the help of a volumetric flow of water were applied at intervals of once every five day and separately for each drought stress level. Irrigation method was drip-tape (type). On the other hand, due to the irrigation of the water through the pipe and the use of drip-tape method, the amount of waste water was considered to be negligible and equal to zero in the surface water and leachate. Measurement of plant pigmentation index was done at full flowering stage using SPAD (Fig. 3). To measure and determine the concentration of nitrogen, phosphorus, potassium, iron, zinc, copper and sodium, were sampled from all the plots from the fully developed leaves of the end parts of the plant and dry ash digestion method was used. In this method, $2 \mathrm{~g}$ of plant material was ashed into an electric furnace and dissolved in $10 \mathrm{cc}$ of chloride. After filtration the volume brought to $100 \mathrm{ml}$. The amounts of potassium and sodium elements were read in the photometric instrument and phosphorus in the spectrophotometer. The amounts of phosphorus and potassium were calculated and expressed as percentage and the amount of Iron, Zinc, Copper and Sodium were calculated and expressed as gram per kilogram of dry matter according to the standard table. Nitrogen content was measured using Kjeldahl method and in and calculated and expressed as percentage. Also, in order to evaluate the reduction or increase of traits in stress and without stress conditions, the percentage of changes of measured traits was calculated.

Data were subjected to analysis of variance (ANOVA) using statistical analysis system (SAS) version 9.1 (SAS Institute Inc., Cary NC, USA). The means were separated using the LSD test $(\mathrm{P} \leq 0.05)$.

\section{Results}

\section{Analysis of variance of traits}

The results of combined analysis of variance showed that the effects of drought stress and mycorrhiza on leaf chlorophyll index and nitrogen, phosphorus, potassium, iron, zinc, copper contents in leaves were significant $(\mathrm{P} \leq 0.01)$. Sodium concentration in leaves was only significantly affected by $(\mathrm{P} \leq 0.01)$ drought stress and seed priming only affected the concentration of copper $(\mathrm{P} \leq 0.05)$. Interaction of irrigation $\times$ mycorrhiza on $\mathrm{P}$ concentration $(\mathrm{P} \leq 0.01)$ and on copper concentration $(\mathrm{P} \leq 0.05)$ and interaction of irrigation $\times$ priming was significant only on the iron concentration in leaf $(\mathrm{P} \leq 0.05)$ (Table 2). 


$$
-340-
$$

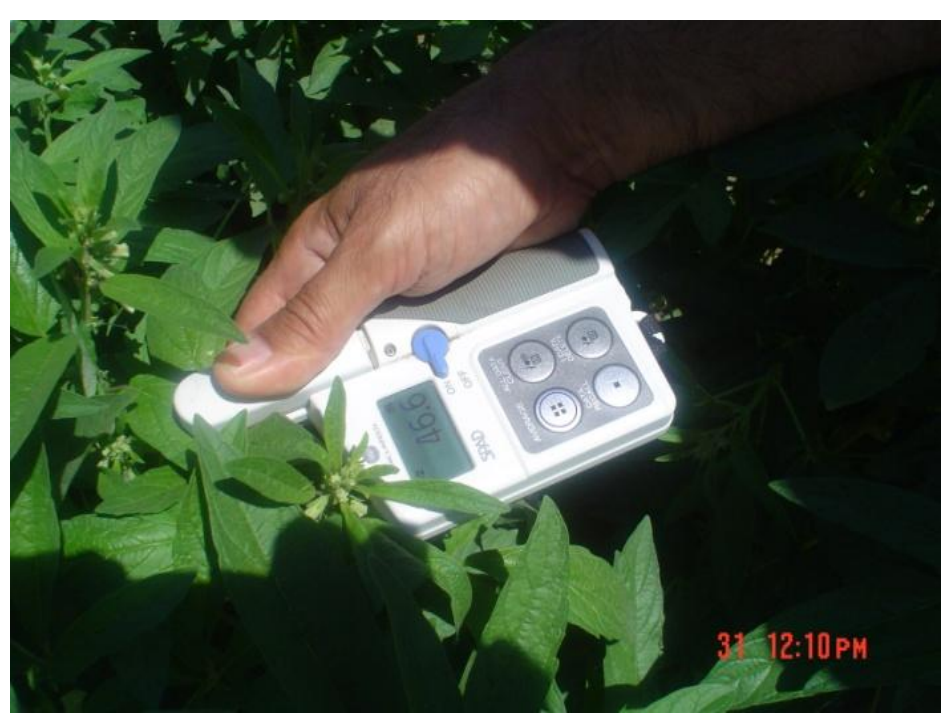

Figure 3. The measurement of chlorophyll index by SPAD in sesame
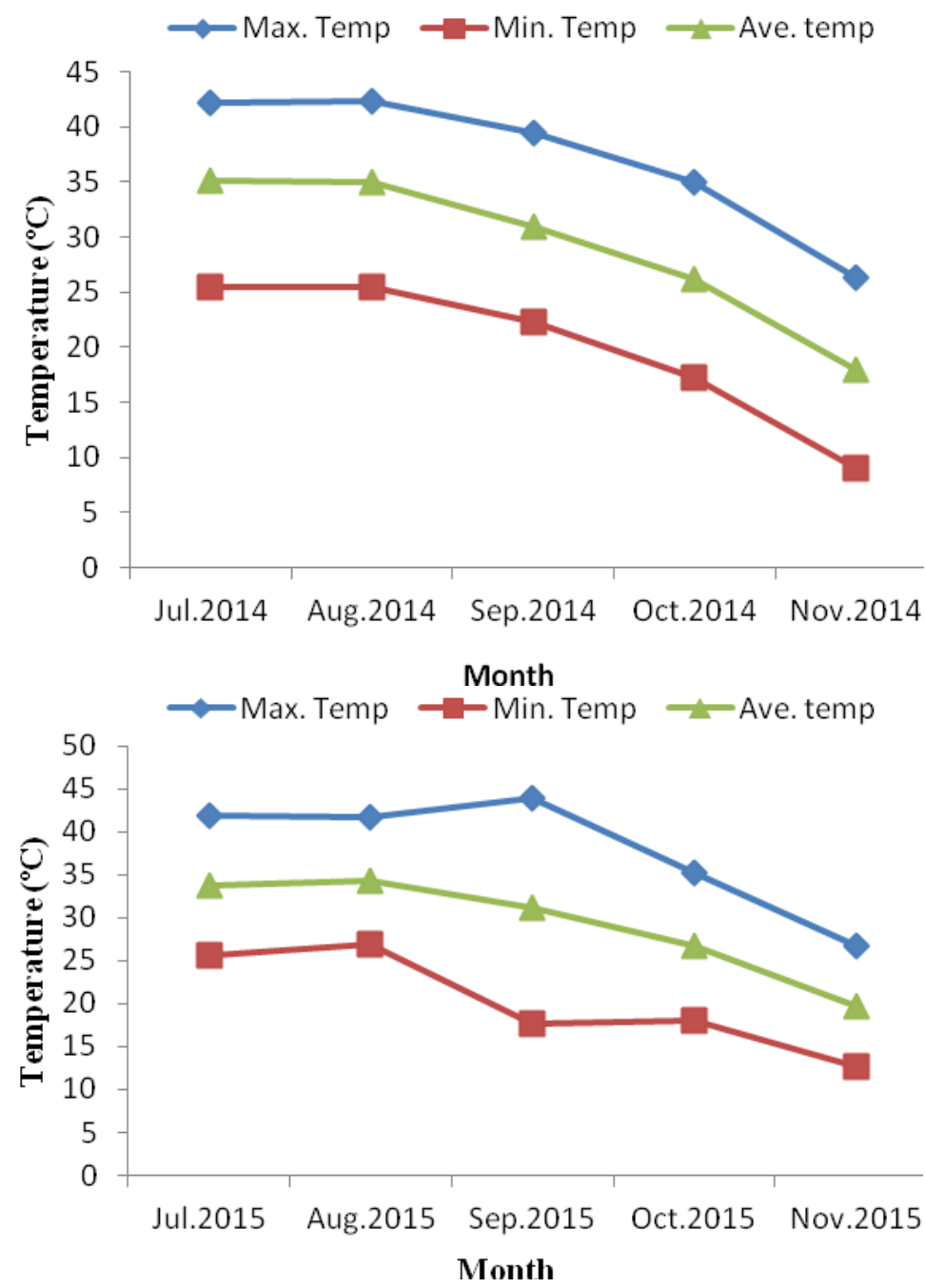

Figure 4. Changes of Temperature during Sesame cultivation period (July to November) 

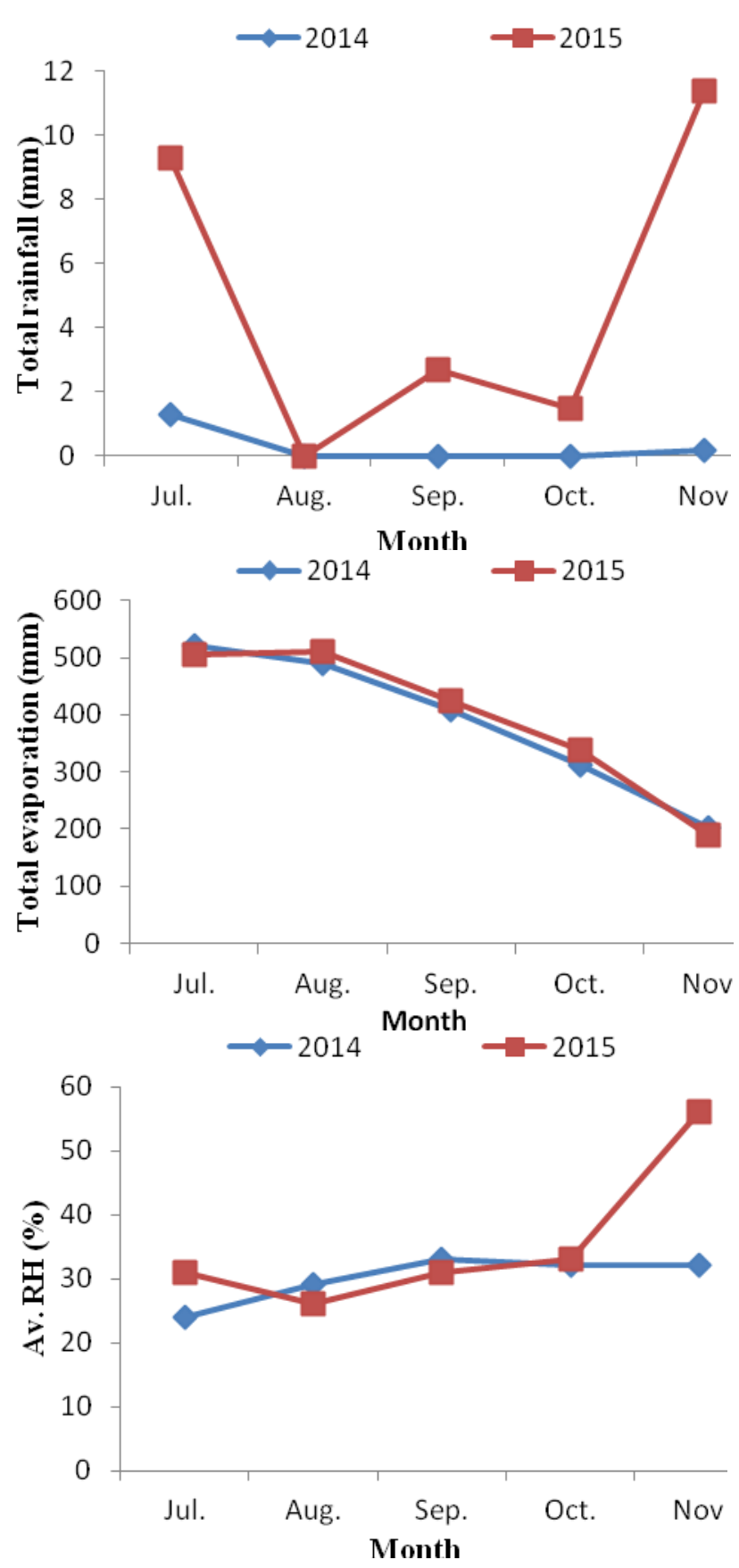

Figure 5. Changes of rainfall, evaporation and relative humidity during Sesame cultivation period (July to November)

\section{Chlorophyll index}

The results showed that with increasing drought stress the chlorophyll index decreased significantly. The mild drought stress reduced the chlorophyll index about $14.30 \%$ and $2.02 \%$, respectively when compared with the optimum irrigation conditions. The highest chlorophyll index (41.67\%) was obtained in the control (Fig. 6). Inoculation with mycorrhizal fungus of $G$. mosseae and $G$. intraradices improved the chlorophyll index by $2.93 \%$ and $2.07 \%$ compared to the (Fig. 7 ). 


$$
-342-
$$

Table 2. Combined analysis of variance (mean squares) for plant characteristics of sesame in irrigation, priming and mycorrhiza treatments

\begin{tabular}{|c|c|c|c|c|c|c|c|c|c|}
\hline \multicolumn{10}{|c|}{ (MS) } \\
\hline S.O.V. & D.F. & $\begin{array}{c}\text { Chlorophyll } \\
\text { index }\end{array}$ & $\mathrm{N}$ conc. & $P$ conc. & $K$ conc. & Fe conc. & Zn conc. & Cu conc. & Na conc. \\
\hline Replication(R) & 2 & 5.34 & 0.1023 & 0.00001 & 0.00115 & 5.5740 & 0.3063 & 7.4413 & 0.01009 \\
\hline Year(Y) & 1 & $0.79^{\mathrm{ns}}$ & $0.0015^{*}$ & $0.00038^{*}$ & $0.02907^{* *}$ & $33.8000^{* *}$ & $52.0540^{* *}$ & $0.1643^{\text {ns }}$ & $0.0053^{\mathrm{ns}}$ \\
\hline $\mathrm{R} \times \mathrm{Y}$ & 2 & 0.60 & 0.0007 & 0.00008 & 0.00190 & 1.1296 & 0.0454 & 0.0252 & 0.0001 \\
\hline Irrigation(I) & 2 & $562.3^{* *}$ & $0.3948^{* *}$ & $0.00882^{* *}$ & $0.02270^{* *}$ & $110.8889^{* *}$ & $69.5238^{* *}$ & $56.6487^{* *}$ & $0.1148^{* *}$ \\
\hline $\mathrm{Y} \times \mathrm{I}$ & 2 & $0.31^{\mathrm{ns}}$ & $0.0097^{\mathrm{ns}}$ & $0.00042^{* *}$ & $0.00114^{\mathrm{ns}}$ & $7.6296^{\mathrm{ns}}$ & $0.1218^{\mathrm{ns}}$ & $0.0098^{\mathrm{ns}}$ & $0.000009^{\mathrm{ns}}$ \\
\hline $\mathrm{R} \times \mathrm{I}$ & 4 & 4.40 & 0.0139 & 0.00006 & 0.00102 & 9.2407 & 1.1948 & 2.2988 & 0.0063 \\
\hline Priming $(\mathrm{P})$ & 2 & $1.05^{\mathrm{ns}}$ & $0.0175^{\mathrm{ns}}$ & $0.00005^{\mathrm{ns}}$ & $0.00186^{\mathrm{ns}}$ & $2.9074^{\mathrm{ns}}$ & $1.4801^{\mathrm{ns}}$ & $5.0804^{*}$ & $0.0011^{\mathrm{ns}}$ \\
\hline Mycorrhiza(M) & 2 & $19.48^{* *}$ & $0.8642^{* *}$ & $0.00332^{* *}$ & $0.02807^{* *}$ & $108.74074^{* *}$ & $20.3769^{* *}$ & $29.0744^{* *}$ & $0.0030^{\mathrm{ns}}$ \\
\hline $\mathrm{Y} \times \mathrm{P}$ & 2 & $0.24^{\mathrm{ns}}$ & $0.0040^{\mathrm{ns}}$ & $0.000001^{\mathrm{ns}}$ & $0.00062^{\mathrm{ns}}$ & $0.16667^{\mathrm{ns}}$ & $0.5632^{\mathrm{ns}}$ & $0.7283^{\mathrm{ns}}$ & $0.00004^{\mathrm{ns}}$ \\
\hline $\mathrm{Y} \times \mathrm{M}$ & 2 & $0.55^{\mathrm{ns}}$ & $0.0313^{\mathrm{ns}}$ & $0.000018^{\mathrm{ns}}$ & $0.00078^{\mathrm{ns}}$ & $0.22222^{\mathrm{ns}}$ & $1.3492^{\mathrm{ns}}$ & $0.0231^{\mathrm{ns}}$ & $0.0001^{\mathrm{ns}}$ \\
\hline $\mathrm{Y} \times \mathrm{I} \times \mathrm{P}$ & 4 & $0.09^{\mathrm{ns}}$ & $0.0299^{\mathrm{ns}}$ & $0.000059^{\mathrm{ns}}$ & $0.00133^{\mathrm{ns}}$ & $0.74074^{\mathrm{ns}}$ & $4.6022^{* *}$ & $0.4924^{\mathrm{ns}}$ & $0.0045^{\mathrm{ns}}$ \\
\hline $\mathrm{Y} \times \mathbf{I} \times \mathrm{M}$ & 4 & $0.17^{\mathrm{ns}}$ & $0.0268^{\mathrm{ns}}$ & $0.000089^{\mathrm{ns}}$ & $0.00204^{\mathrm{ns}}$ & $0.40740^{\mathrm{ns}}$ & $0.2492^{\mathrm{ns}}$ & $1.9194^{\mathrm{ns}}$ & $0.0022^{\mathrm{ns}}$ \\
\hline $\mathrm{Y} \times \mathrm{P} \times \mathrm{M}$ & 4 & $0.23^{\mathrm{ns}}$ & $0.0174^{\mathrm{ns}}$ & $0.000079^{\mathrm{ns}}$ & $0.00042^{\mathrm{ns}}$ & $0.44248^{\mathrm{ns}}$ & $0.1542^{\mathrm{ns}}$ & $3.2489^{\mathrm{ns}}$ & $0.0006^{\mathrm{ns}}$ \\
\hline $\mathrm{I} \times \mathrm{P}$ & 4 & $1.50^{\mathrm{ns}}$ & $0.0152^{\mathrm{ns}}$ & $0.000085^{\mathrm{ns}}$ & $0.00129^{\mathrm{ns}}$ & $7.79629^{*}$ & $0.3837^{\mathrm{ns}}$ & $2.6395^{\mathrm{ns}}$ & $0.0033^{\mathrm{ns}}$ \\
\hline $\mathrm{I} \times \mathrm{M}$ & 4 & $0.24^{\mathrm{ns}}$ & $0.0153^{\mathrm{ns}}$ & $0.00086^{* *}$ & $0.00126^{\mathrm{ns}}$ & $2.29629^{\mathrm{ns}}$ & $1.0016^{\mathrm{ns}}$ & $4.2674^{*}$ & $0.0017^{\mathrm{ns}}$ \\
\hline $\mathrm{P} \times \mathrm{M}$ & 4 & $0.28^{\mathrm{ns}}$ & $0.0091^{\mathrm{ns}}$ & $0.00012^{\mathrm{ns}}$ & $0.00067^{\mathrm{ns}}$ & $3.59260^{\mathrm{ns}}$ & $0.7354^{\mathrm{ns}}$ & $3.5101^{\mathrm{ns}}$ & $0.0043^{\mathrm{ns}}$ \\
\hline $\mathrm{I} \times \mathrm{P} \times \mathrm{M}$ & 8 & $0.82^{\mathrm{ns}}$ & $0.0109^{\mathrm{ns}}$ & $0.00011^{\mathrm{ns}}$ & $0.00187^{\mathrm{ns}}$ & $4.70370^{\mathrm{ns}}$ & $1.5807^{\mathrm{ns}}$ & $1.9562^{\mathrm{ns}}$ & $0.0014^{\mathrm{ns}}$ \\
\hline $\mathrm{Y} \times \mathrm{I} \times \mathrm{P} \times \mathrm{M}$ & 8 & $0.16^{\mathrm{ns}}$ & $0.0246^{\mathrm{ns}}$ & $0.00012^{\mathrm{ns}}$ & $0.00315^{\mathrm{ns}}$ & $0.24074^{\mathrm{ns}}$ & $2.3478^{\mathrm{ns}}$ & $0.5035^{\mathrm{ns}}$ & $0.0006^{\mathrm{ns}}$ \\
\hline C.V. (\%) & - & 3.28 & 11.56 & 5.37 & 4.04 & 4.20 & 4.18 & 12.28 & 4.15 \\
\hline
\end{tabular}

ns: non- significant; $*$ and $* *$ : significant at $5 \%$ and $1 \%$ probability levels, respectively

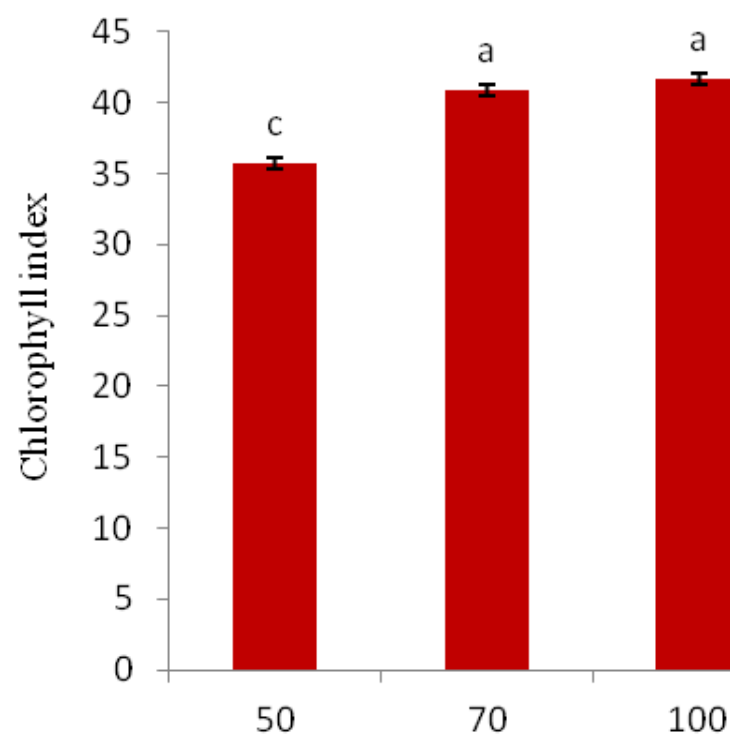

Drought stress levels

Figure 6. Effect of drought stress levels on chlorophyll index 


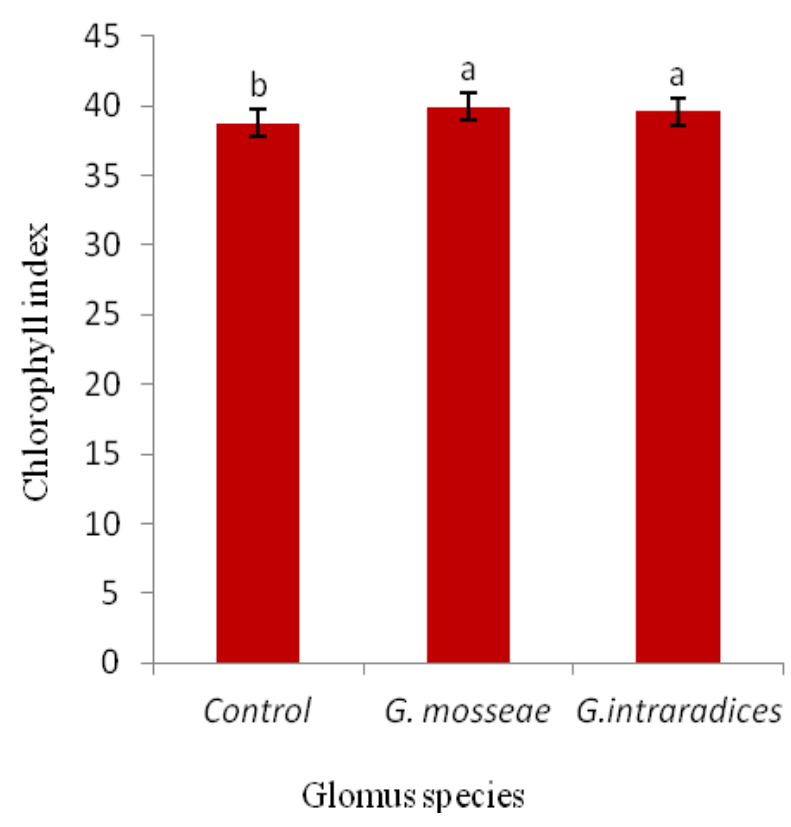

Figure 7. Effect of Glomus species on chlorophyll index

\section{Nitrogen concentration}

The results of this study showed that nitrogen concentration of leaf was decreased with increasing drought stress. According to the results, the highest nitrogen concentration was obtained for (control) with an average of $1.31 \%$, while the lowest was obtained in severe drought stress conditions with an average of $1.14 \%$. Sever and mild drought stresses reduced the nitrogen concentration by $12.81 \%$ and $8.67 \%$, respectively, when compared with optimal irrigation. Soil water reduction in stress treatments caused nitrogen supply and reduced absorption and concentration of nitrogen in the plant (Fig. 8).

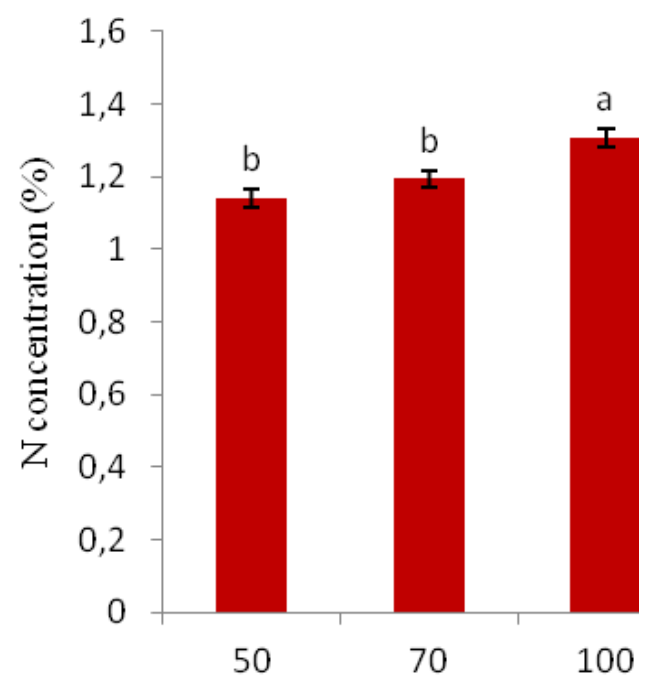

Drought stress levels

Figure 8. Effect of drought stress levels on $N$ concentration 
Inoculation with $G$. mosseae and $G$. intraradices mycorrhizal fungi increased nitrogen concentration to the $17.05 \%$ and $15.74 \%$ when compared with control (Fig. 9).

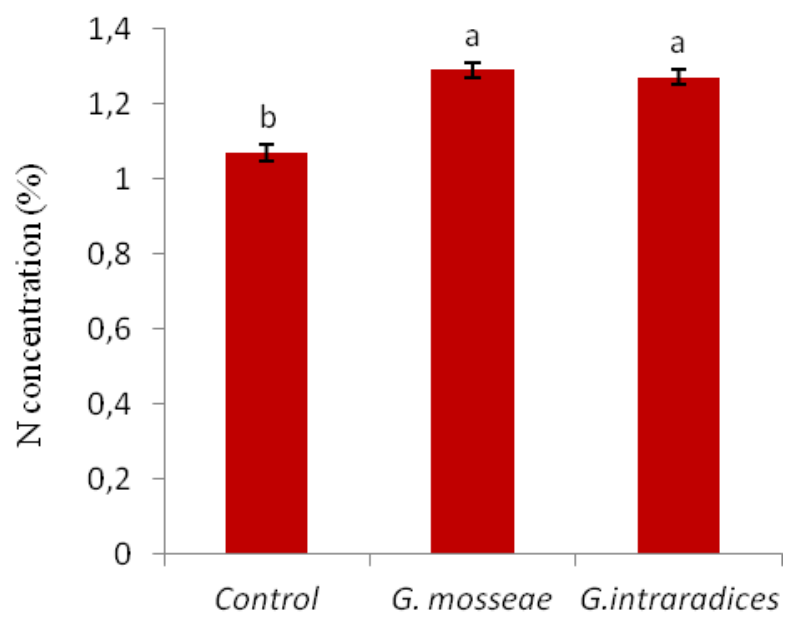

Glomus species

Figure 9. Effect of Glomus species on N concentration

\section{Phosphorous concentration}

Based on the results of this study, drought stress decreased phosphorus concentration in the leaves as well as the nitrogen. The highest concentration of $\mathrm{P}$ was obtained for control with an average of $0.16 \%$, while the lowest was obtained in severe drought stress conditions with an average of $0.13 \%$. Sever and mild drought stress, reduced phosphorus concentration to $15.96 \%$ and $6.96 \%$, respectively when compared with optimal irrigation (Fig. 10).

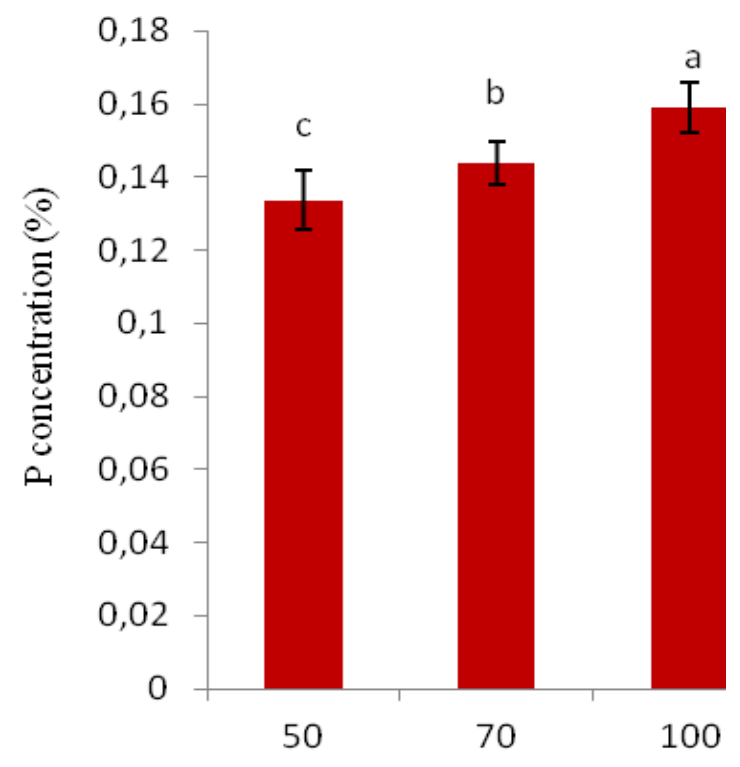

Drought stress levels

Figure 10. Effect of drought stress levels on P concentration 
Inoculation of soil with $G$. mosseae and $G$. intraradices mycorrhizal fungi increased the concentration of phosphorus to 9.54 and $8.54 \%$ when compared with the control (Fig. 11). The interaction of drought stress and mycorrhiza was significant for phosphorus concentration $(\mathrm{P} \leq 0.01)$ (Table 2). This indicates that the effect of fungi on the concentration of phosphorus is not independent from effect of stress and is affected by phosphorus. The highest concentration of phosphorus in irrigation conditions was related to the control and inoculation with $G$. mosseae species with an average of $0.17 \%$ and the lowest was obtained in severe drought stress and without usage of mycorrhizal fungus with an average of $0.12 \%$ (Fig. 12). The results also showed that there were no significant differences between two species of $G$. mosseae and $G$. intraradices for phosphorus concentration in leaf.

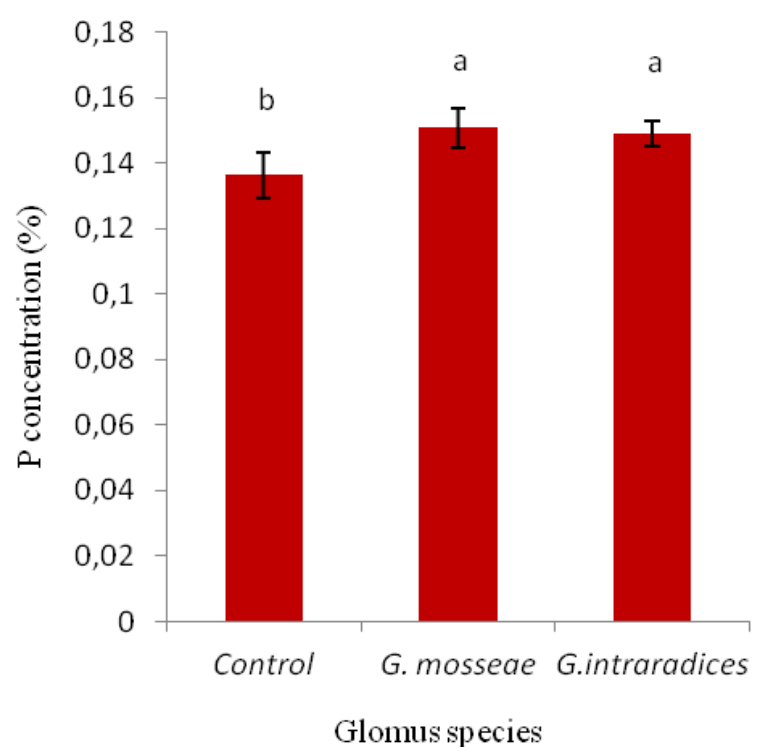

Figure 11. Effect of Glomus species on P concentration

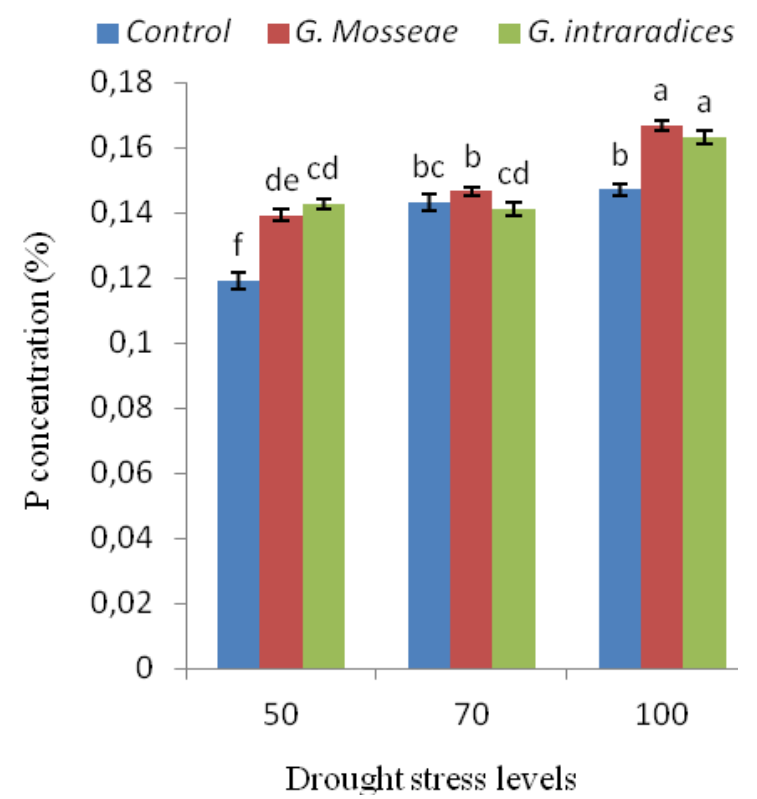

Figure 12. Interaction effect of Glomus fungi and drought stress on P concentration 


\section{Potassium concentration}

Drought stress increased potassium concentration in leaf. Based on the results the highest concentration of potassium in the leaf was obtained under severe stress conditions with an average of $1.07 \%$ and the lowest in control with a mean of $1.03 \%$. Sever and mild drought stresses increased potassium concentration by $3.8 \%$ and $2.3 \%$ in comparison with optimal irrigation (Fig. 13). Inoculation with G. mosseae and $G$. intraradices mycorrhizal fungi increased the concentration of potassium to 4.06 and $3.19 \%$ in comparison with non-inoculated fungi (Fig. 14). The results also showed that there were no significant differences between two species of $G$. mosseae and $G$. intraradices for potassium concentration in leaf.

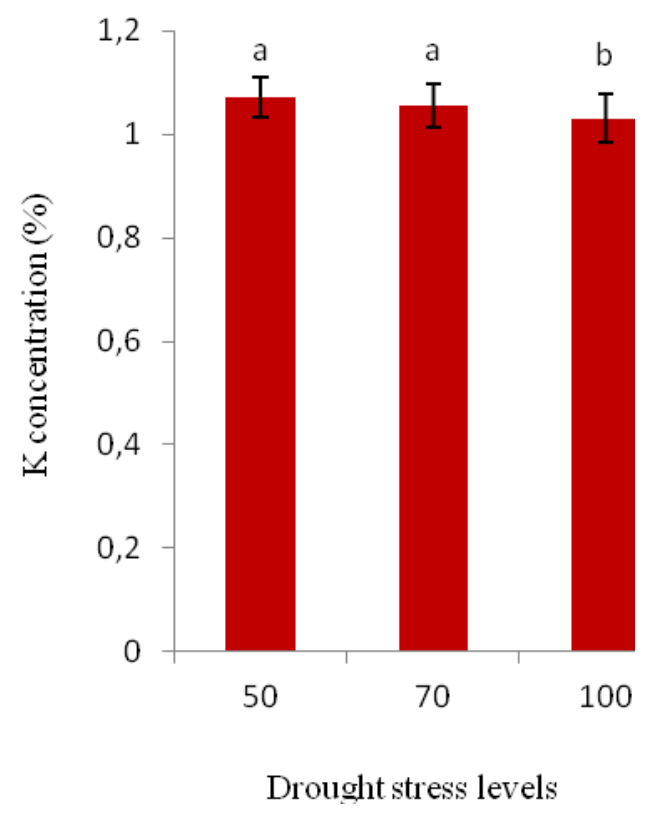

Figure 13. Effect of drought stress levels on K concentration

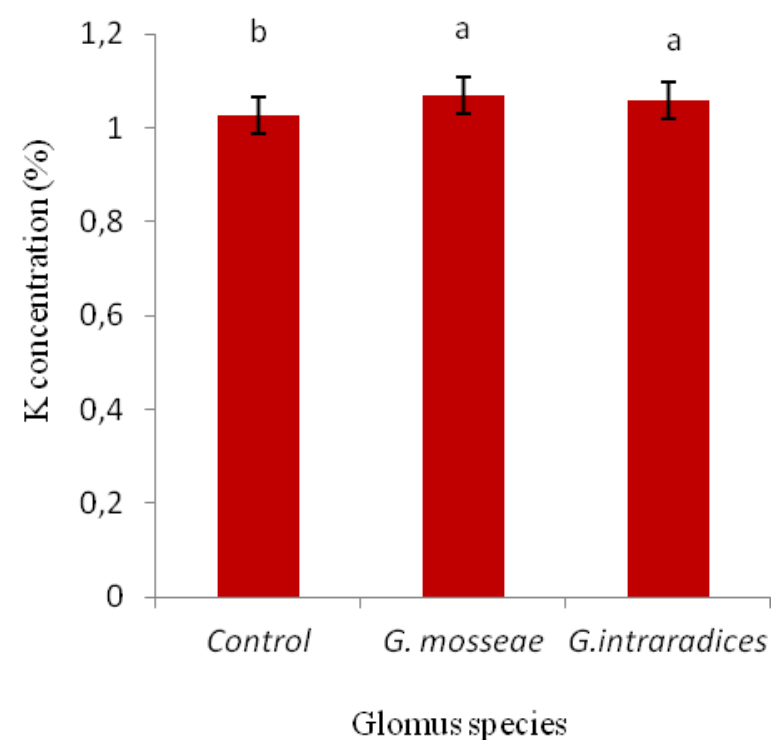

Figure 14. Effect of Glomus fungi on K concentration 


\section{Iron concentration}

The results showed that the concentration of iron in the leaf increased with drought stress applies. Based on the results the highest iron concentration in the leaf under severe drought stress was obtained with an average of $39.22 \mathrm{mg} / \mathrm{kg}$ leaf dry matter and the lowest in control with a mean of $36.44 \mathrm{mg} / \mathrm{kg}$ leaf dry matter. Intense and mild drought stresses increased the iron concentration to 7.09 and $5.2 \%$, respectively compared with optimal irrigation (Fig. 15). Inoculation with G. mosseae and $G$. intraradices mycorrhizal fungi improved the iron concentration to 6.67 and $5.94 \%$ compared with non-inoculated mycorrhizal fungi (Fig. 16).

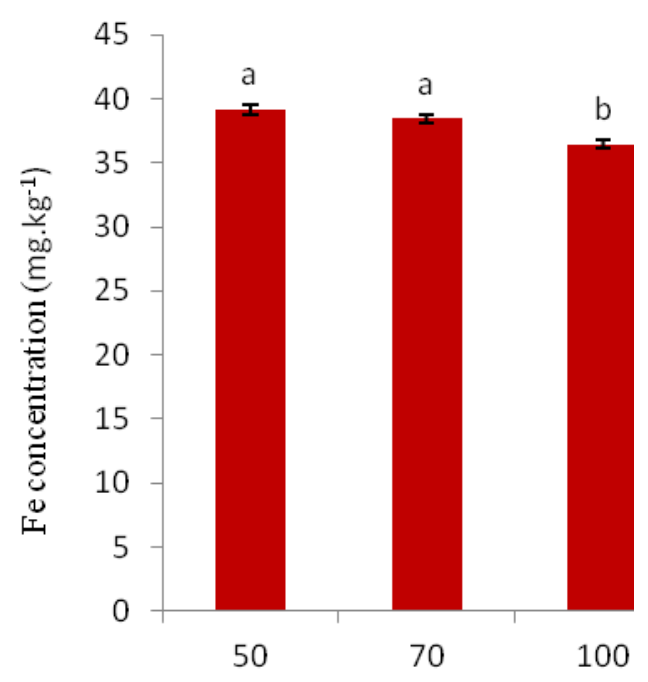

Drought stress levels

Figure 15. Effect of drought stress levels on Fe concentration

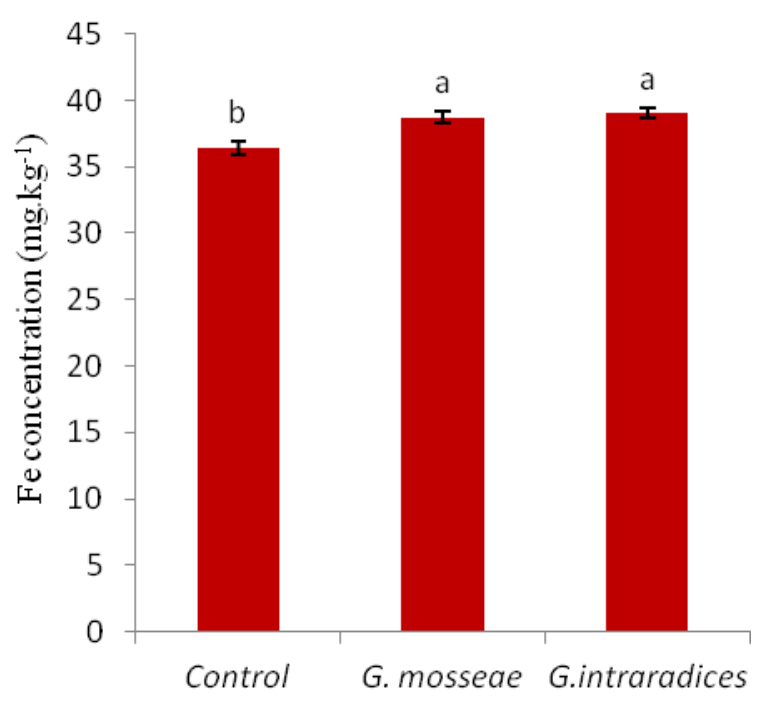

Glomus species

Figure 16. Effect of Glomus fungi on Fe concentration 
The interaction of drought stress and priming on the concentration of Fe in leaf $(\mathrm{P} \leq 0.05)$ was significant. The highest iron concentration was observed under severe stress conditions (irrigation equivalent to $50 \%$ water requirement) and hydro-priming with an average of $39.50 \mathrm{mg} / \mathrm{kg}$ leaf dry matter and the lowest in control and without priming with mean of $35.55 \mathrm{mg} / \mathrm{kg}$ leaf dry matter (Fig. 17).

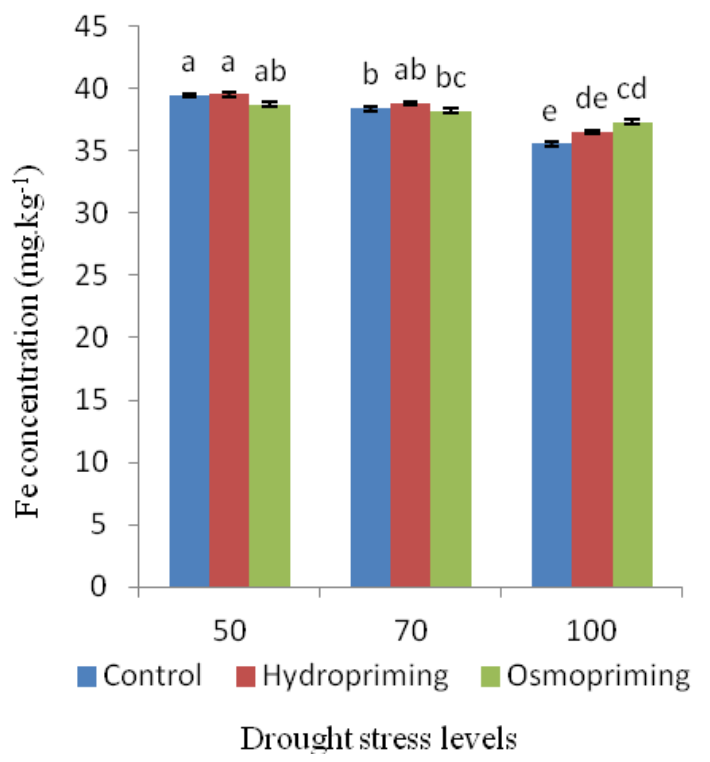

Figure 17. Interaction effect of Glomus fungi and drought stress on Fe concentration

\section{Zinc concentration}

Drought stress increased zinc concentration in the leaves. Based on the results the highest zinc concentration was observed in severe drought stress conditions with an average of $26.95 \mathrm{mg} / \mathrm{kg}$ leaf dry matter and the lowest in control with an average of $24.73 \mathrm{mg} / \mathrm{kg}$ leaf dry matter. Severe and mild drought stress increased concentration of zinc in comparison with optimal irrigation by 8.24 and $5.75 \%$, respectively (Fig. 18).

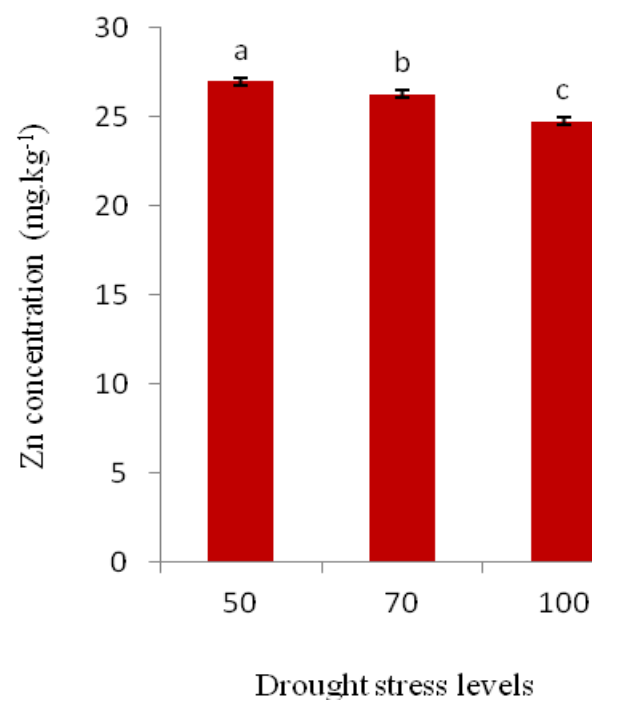

Figure 18. Effect of drought stress levels on Zn concentration 
Inoculation with mycorrhizae of $G$. mosseae and $G$. intraradices increased zinc concentrations up to $4.14 \%$ and $3.95 \%$ compared to the non-inoculated with mycorrhizal fungi (Fig. 19).

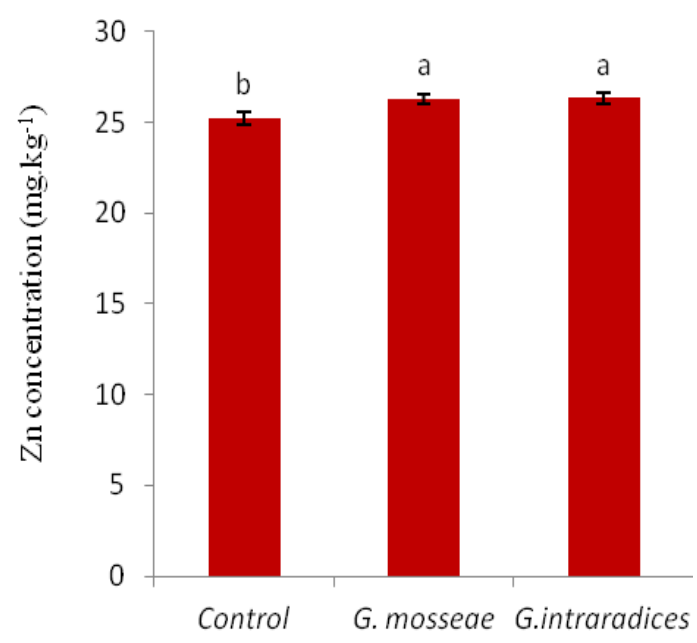

Glomus species

Figure 19. Effect of Glomus fungi on Zn concentration

\section{Copper concentration}

The results showed that the concentration of copper in the leaf increased with drought stress. Based on the results the highest concentration of copper in severe drought stress conditions was obtained with an average of $10.89 \mathrm{mg} / \mathrm{kg}$ leaf dry matter and the lowest in control with an average of $8.87 \mathrm{mg} / \mathrm{kg}$ leaf dry matter. Severe and mild drought stresses increased the copper concentration by $18.55 \%$ and $12.78 \%$, respectively, as compared to the optimal irrigation (Fig. 20).

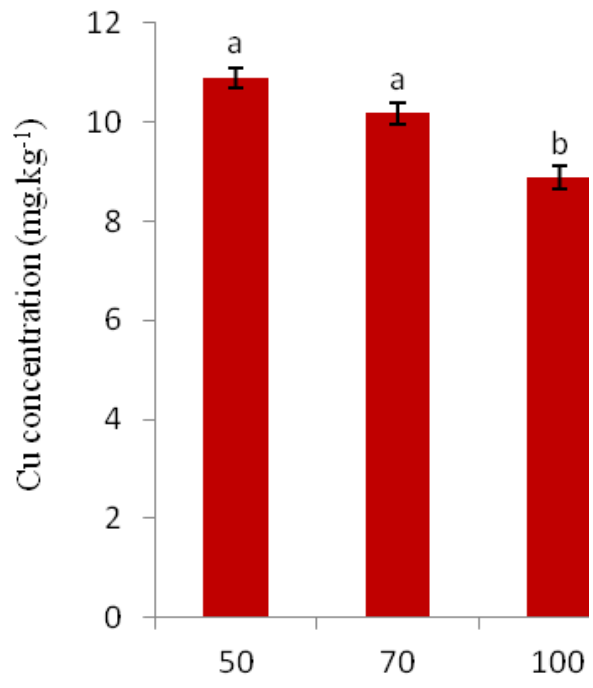

Drought stress levels

Figure 20. Effect of drought stress levels on Cu concentration 
Inoculation with G. mosseae and G. intraradices mycorrhizal fungi increased the copper concentration to $12.72 \%$ and $11.71 \%$ in comparison with non-inoculation with mycorrhizal fungus (Fig. 21).

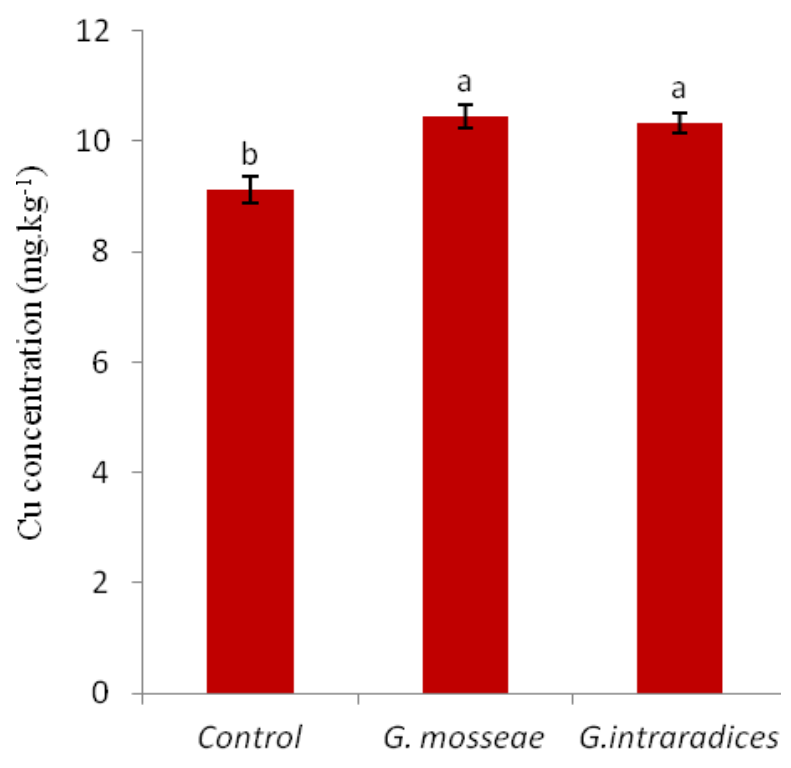

Glomus species

Figure 21. Effect of Glomus species on Cu concentration

Seed priming increased concentration of copper in the leaves to 3.49 and $2.48 \%$ than non-priming (Fig. 22).

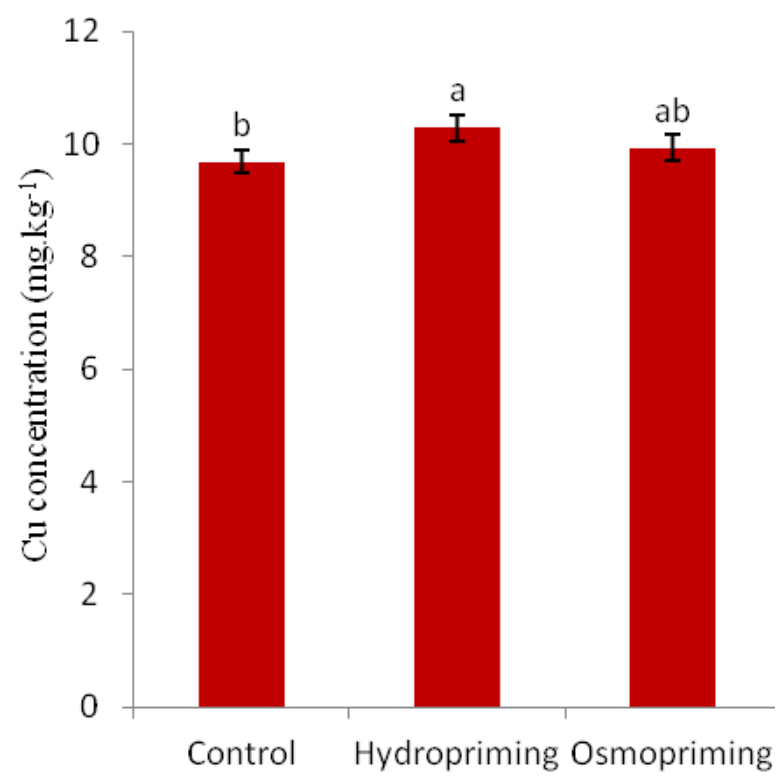

\section{Priming}

Figure 22. Effect of priming levels on $\mathrm{Cu}$ concentration 
The effect of drought stress and mycorrhiza on the concentration of copper in leaf was significant at $5 \%$ probability level. The highest concentration of copper was obtained in severe drought stress and inoculation with $G$. mosseae $11.64 \mathrm{mg} / \mathrm{kg}$ dry matter and the lowest in control and without usage of mycorrhizal fungus with an average of 8.08 $\mathrm{mg} / \mathrm{kg}$ leaf dry matter (Fig. 23).

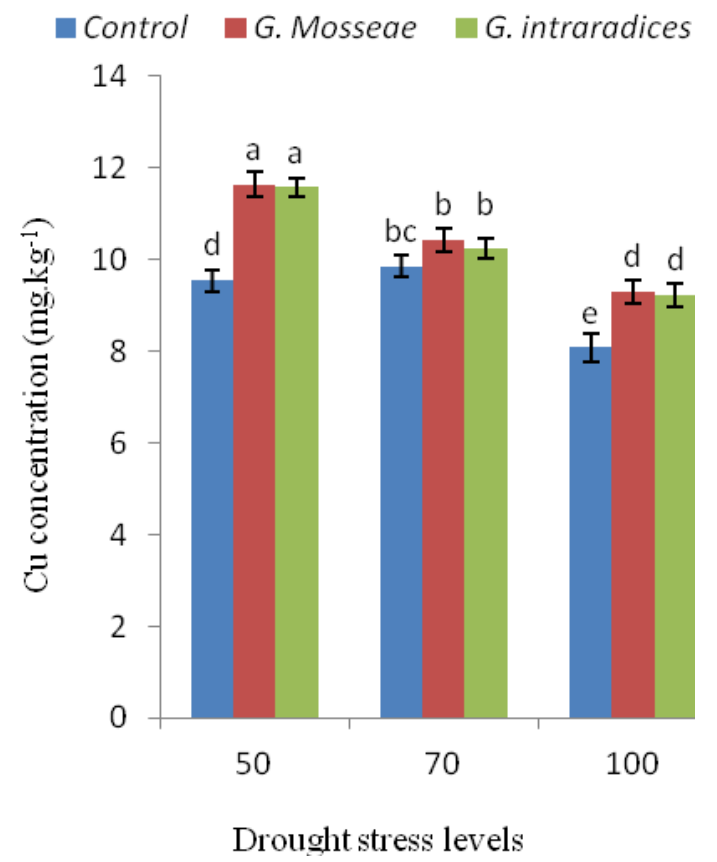

Figure 23. Interaction effect of Glomus species and drought stress on Cu concentration

\section{Sodium concentration}

The results showed that by applying drought stress, the concentration of sodium in the leaf was increased. Based on the results the highest concentration of sodium was obtained in the leaf under severe stress conditions with an average of $1.14 \mathrm{mg} / \mathrm{kg}$ leaf dry matter and the lowest in control with an average of $1.05 \mathrm{mg} / \mathrm{kg}$ leaf dry matter. Severe and mild drought stresses increased the sodium concentration in the leaf to $7.89 \%$ and $4.54 \%$ respectively when compared with optimal irrigation (Fig. 24).

\section{Discussion}

Under our conditions of experiment, the results showed that with increasing drought stress the chlorophyll index decreased significantly. Reduction of chlorophyll content in drought stress conditions has been reported in sunflower (Gholam-Hosseini and Ghalavand, 2008). Dehydration stress through chlorophyllase and peroxidase enzymes activities in plants lead to chloroplast destruction and chlorophyll content reduction (Misra and Sricastatva, 2000). The plant's water conditions have important effects on leaf chlorophyll (Vidal et al., 1999). Reducing chlorophyll content due to drought stress is related to the increase of oxygen radicals in the cells (Schutz and Fangmeir, 2001). It seems that chlorophyll content reduction under drought conditions is due to chlorophyllase, peroxidase activities and consequently chlorophyll degradation 
(Ahmadi and Ceiocemardeh, 2004). The reduction of chlorophyll content in this study was consistent with the results of other researchers (Zhang et al., 2006; Sanchez-Blanco et al., 2006). The highest rate of photosynthesis and chlorophyll content in maze plant was obtained when inoculated with mycorrhiza and bacteria (Jahan et al., 2007).

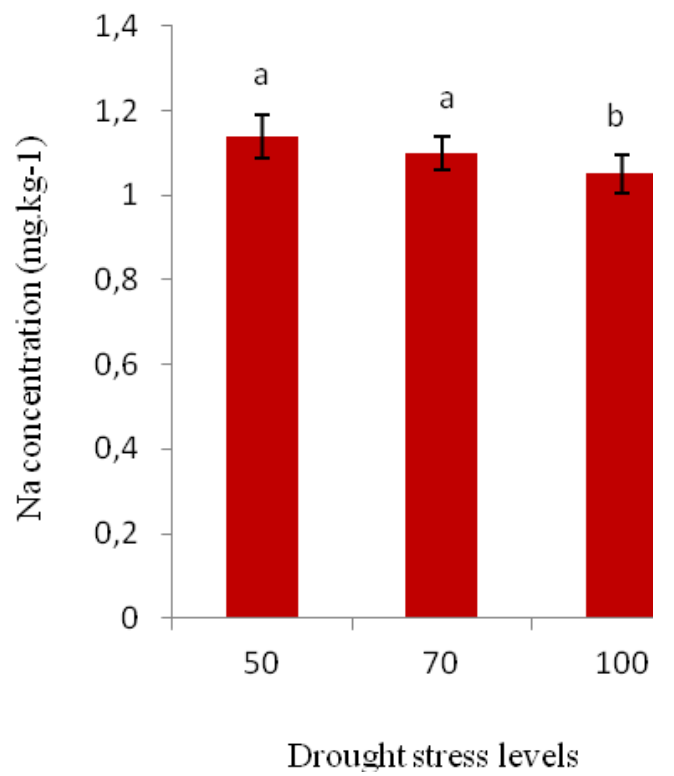

Figure 24. Effect of drought stress levels on Na concentration

The results of this study showed that nitrogen concentration of leaf was decreased with increasing drought stress. Under severe stress conditions, plant roots are exposed to water deficit and decreases nitrogen absorption from soil since nitrogen uptake is function of transpiration stream (Saneoka et al., 2004), which is consistent with the results of this experiment. Mass flow plays a dominant role in the supply of nitrogen (especially in the form of nitrate) to the root and its absorption by the plant. On the other hand, the amount of mass flow depends on the amount of soil water. Soil water reduction in stress treatments caused nitrogen supply and reduced absorption and concentration of nitrogen in the plant. One of the drought stress effects is modulation of root development. In this case, horizontal growth decreases and vertical root growth increases. It is mentioned that root growth is closely related to the absorption of phosphorus and nitrogen from soil (Fan and Mackenzie, 1994). Based on the results of this study, drought stress decreased phosphorus concentration in the leaves as well as the nitrogen. It seems that decrease of phosphorus concentration under drought stress is because of the low mobility of phosphorus in the soil because the supply of phosphorus to root is due to diffusion and the amount of soil moisture influences the rate of diffusion. Of course, it should be considered that soils differ in terms of the phosphorus availability and stabilizing for plants (Kafi et al., 2010). Inoculation of soil with $G$. mosseae and $G$. intraradices mycorrhizal fungi increased the concentration of phosphorus. These results are consistent with the results of (Auge, 2001). Inoculation with mycorrhiza fungi caused development of root system and increased the concentration of phosphorus in the leaf. The effect of mycorrhizal fungus on the growth of host plant under drought stress has been reported through improvement of phosphorus availability because access to the phosphorus decreases in dry soils 
(Subramanian et al., 2006). Thus, reducing soil moisture reduces nutrients, especially phosphorus from soil to the root. Therefore, mycorrhiza increases phosphorus uptake by plant roots under drought stress and without stress (Hetrick et al., 1996). Phosphorus uptake increased by absorption from roots (Smith and Read, 1997; Cui and Caldwell, 1996). The symbiosis with the G. intraradices fungus in pepper resulted in an increase in leaf area ratio, which is due to mycorrhizal effect on increasing phosphorus content in this plant (Demir, 2004). In general, the use of fungi increased the concentration of phosphorus in the leaf rather than its application. It can be stated that fungus developed root system through its mycelium and rays, and caused the plant roots to use rhizosphere more widely (Bolan, 1991).

Stress increased potassium concentration in leaf. Reports from various researchers also confirmed that potassium absorption increased during drought stress. During drought stress plants increase $\mathrm{K}$ concentration in the root due to the increased drought resistance. Increasing potassium adsorption has a positive effect on photosynthesis, growth and leaf area index, open and closing of stomata regulation, transpiration decrease (Abd-EL-Moez, 1996; Gonzales and Salas, 1995). The other reason which researchers have suggested for increase of potassium adsorption in plants under drought stress, is continuous dry and drying in the soil, that releases $\mathrm{K}$ from clay layers and this phenomenon increases potassium uptake (Logan et al., 1997). Inoculation with $G$. mosseae and $G$. intraradices mycorrhizal fungi increased the concentration of potassium. Mycorrhizal inoculation increased moisture availability and provided more access to nutrients. Some studies confirmed that mycorrhizal symbiosis improved the active root system to increase the absorption of water and nutrient (Kapoor et al., 2004). The results showed that the concentration of iron in the leaf increased with drought stress applies. Inoculation with $G$. mosseae and $G$. intraradices mycorrhizal fungi improved the iron concentration. It seems that increasing absorption of nutrients is mainly due to the release of mycorrhizal mycelia and the formation of an additional complementary absorption system to the root system of the plant, which makes it possible to use more volumes of soil that the feeder roots do not have access to. Mycorrhizal fungi control the problems of reducing water absorption under conditions of depleted moisture in the root environment by improving the hormonal status of the plants in controlling the opening and closing of leaf stomata and increasing the water absorption due to the spread of the hyphae network (Roldan-Fagardo et al., 1982). The interaction of drought stress and priming on the concentration of Fe in leaf $(\mathrm{P} \leq 0.05)$ was significant (Table 2). This suggests that the seed priming effect on the concentration of iron is dependent of effect of stress. Drought stress increased zinc concentration in the leaves. Limited reports have been published on zinc ion accumulation under stress conditions in plant aerial organs. In corn (Alizadeh, 2010) and in canola (Nasri et al., 2008), reported that dehydration stress increased zinc concentrations in plant aerial organs, which is consistent with the results of this study. Inoculation with mycorrhizae of $G$. mosseae and $G$. intraradices increased zinc concentrations. Mycorrhizal symbiosis increases the absorption of zinc by increasing the length of the roots and also increasing the absorption by the fungal roots (Kothari et al., 1991). The concentration of copper in the leaf increased with drought stress, inoculation with G. mosseae and G. intraradices mycorrhizal fungi and seed priming. In justifying the function of priming, we can point to the rapid and favorable establishment of the plant and its further use of nutrients, soil moisture and solar radiation. Primed seeds are germinated sooner, and their various biological stages are also more likely to result. This natural adaptation of 
stressful living factor changes with the phonological stages of the plant, and the damage to the plant will be reduced. Foreign mycelia of Mycorrhiza arbuscular fungi mainly contain hyphae and fungal spores. External hyphae extend in the soil and produce high absorption of copper ( $\mathrm{Li}$ et al., 1991). In corn, mycorrhizal symbiosis increased the concentration of copper in the shoot but did not have a significant effect on underground organs (Kothari et al., 1991). Mycorrhizal fungi increased their efficiency in absorption of water and nutrients; in particular, phosphorus, zinc, and copper with an extensive hefy network and increased absorption rate of roots (Marschner and Dell, 1994). The results showed that by applying drought stress, the concentration of sodium in the leaf was increased. The accumulation of sodium in the tissue is due to more absorption by the root and more drainage from the stem to the leaves. Osmotic balance of plants carries out by absorbing more sodium that make plants enable to absorb more water (Munns and James, 2003). It was reported that with increasing stress, the amount of sodium accumulation in the leaf increased in wheat plant (Bagheri, 2009). In sugar beet, it was stated that under drought stress, sodium and potassium accumulated greatly in roots and stems (Ghoulam et al., 2002). The increase in sodium due to drought stress has also been reported by other researchers (El-Tayeb, 2006). This increase has been proposed as a defense mechanism that helps plants under stress to increase the amount of sodium in order to regulate the osmotic pressure of cells and tissues under stress, in order to improve the absorption of water from soil.

\section{Conclusion}

In general, the results of this study showed that drought stress reduced the concentration of phosphorus and nitrogen, but increased potassium, zinc, iron, copper and sodium in the leaves. Also, symbiosis with mycorrhizal fungi increased concentration of all of the nutrients in sesame except for sodium. Also, it was found that the positive effects of mycorrhizal symbiosis were not dependent to fungi species. Mycorrhiza absorbs and transports water and nutrients to the plant through the release of mycelia's in the micro porous pores, and also improves the plant's aquatic relationships which causes increasing turgor pressure. Therefore, under poor water conditions the use of mycorrhizal fungi, reduces water consumption and provides a suitable source for increasing drought tolerance in plants. Based on the results of this study it can be recommended, sesame farms in the country get inoculated by inoculum of mycorrhizal fungi arbuscular and benefit from positive effects of this symbiosis in yield increase and nutrient uptake, especially phosphorus, nitrogen, potassium, iron and copper and develop Plant growth conditions.

\section{REFERENCES}

[1] Abd-EL-Moez, M. R. (1996): Dry matter yield and nutrient uptake of corn as affected by some organic wastes applied to a sandy soil. - Annals of Agricultural Science 34: 13191330 .

[2] Ahmadi, A., Ceiocemardeh, A. (2004): Effect of drought stress on soluble carbohydrate, chlorophyll and proline in four adopted Wheat cultivars with various climate of Iran. Iranian Journal of Agriculture Science 35: 753-763. 
[3] Alizadeh, O. (2010): Evaluation effect of water stress and nitrogen rates on amount of absorbtion some macro and micro element in corn plant mycorrhiza and non-mycorrhiza. - Advances in Natural and Applied Science 4(2): 153-158.

[4] Alsamowal, M. M., Hadad, M. A., Sharif, Z. (2016): Response of sesame (Sesasum indicum L.) to vesicular arbuscular mycorrhiza (VAM) and mineral phosphorus additions at different moisture regimes under greenhouse conditions in Sudan. - International Journal of Scientific and Research Publications 6(8): 82-88.

[5] Auge, R. M. (2001): Water relations, drought and vesicular- arbuscular mycorrhizal symbiosis. - Mycorrhiza 11: 3-42.

[6] Babajide, P. A., Fagbola, O. (2014): Growth, yield and nutrient uptakes of sesame (Sesamum indicum linn.) as influenced by biofertilizer inoculants. - International Journal of Current Microbilogy and Applied Sciences 3(8): 859-879.

[7] Bagheri, A. (2009): Effect of droughtstress on yield, yield components and ioncontent in wheat cultivars. - Journal of Plant Ecophysiology 1(3): 16-30 (in Farsi).

[8] Bolan, N. S. (1991): A critical review on the role of Mycorrhizal fungi in the uptake on phosphorus by plants. - Plant and Soil 134: 187-207.

[9] Boureima, S., Diouf, M., Diop, T. A., Diatta, M., Leye, E. M., Ndiaye. F., Seck, D. (2007): Effects of arbuscular mycorrhizal inoculation on the growth and the development of sesame (Sesamum indicum L.). - African Journal of Agricultural Research 3(3): 234238.

[10] Cui, M., Caldwell, M. M. (1996): Facilitation of platphosphate acquisition by arbuscular mycorrhiza from enriched soil patches roots and hyphaeexploiting the same soil volume. - New Phytologist 133(3): 453-460.

[11] Demir, S. (2004): Influence of arbuscular mycorrhizaon some physiological growth parameters of pepper. - Turkish Journal of Biology 28: 85-90.

[12] El-Tayeb, M. A. (2006): Differential response of two Viciafaba cultivars to drought: growth, pigments, lipid peroxidation, organic solutes, Catalas and peroxidase activity. Acta Agronomica Hungarica 54: 25-37.

[13] Farshi, A., Shariati, M., Jarollahi, R., Ghaemi, M., Shahabifar, M., Tallaei, M. M. (1998): An Estimate of Water Requirement of Main Field Crops and Orchards in Iran (Vol. 1: Field crops). - Soil and Water Research Institute, Agricultural Education Publication, Karaj.

[14] Fan, M. X., Mackenzie, A. F. (1994): Corn yield and phosphorus uptake with bonded urea and phosphate mixtures. - Soil Science Society of America Journal 58: 249-255.

[15] Fatemy, F., Evans, K. (1986): Effects of Globoder arostochiensis and water stress on shoot and root growth and nutrient uptake of potatoes. - Revune Nematol 9: 181-184.

[16] Feng, G., Zhang, F. S., Li, X. L., Tian, C. Y., Tang, C. (2002): Improved tolerance of maize plants to salt stress by arbuscular mycorrhiza is related to higher accumulation of soluble sugars in roots. - Mycorrhiza 12: 185-190.

[17] Gholam-Hosseini, M., Ghalavand, A. (2008): The impact of irrigation and fertilizer treatments on yield and metal concentration in leaves and sunflower seeds. - Research and Development in Agriculture and Horticulture 79: 91-100 (in Farsi).

[18] Ghoulam, C., Foursy, A., Fares, K. (2002): Effects of salt stress on growth, inorganic ions and proline accumulation in relation to osmotic adjustment in five sugar beets cultivars. Environmental Expert Botany 47: 39-50

[19] Gonzales, P. R., Salas, M. L. (1995): Improvement of the growth, grain yield, and nitrogen, phosphorus and potassium nutrition of grain corn through weed control. Journal of Plant Nutrition 18: 3313-3324.

[20] Harikumar, V. S. (2013): Symbiotic response of sesame (Sesamum indicum L.) to different indigenous arbuscular mycorrhizal fungi (AMF) from rice fallows of Kerala, India. - Journal of Agricultural Technology 9(6): 1631-1640.

[21] Hassanzadeh, M., Ebadi, A., Panahyan-e-Kivi, M., Eshghi, A. G., Jamaati-e-Somarin, Sh., Saeidi, M., Zabihi-e-Mahmoodabad, R. (2009): Evaluation of drought stress on 
relative water content and chlorophyll content of sesame (Sesamum indicum L.) genotypes at early flowering stage. - Research Journal of Enviroment Sciences 3(3): 345350.

[22] Hetrick, B. A. D., Wilson, G. W. T., Todd, T. C. (1996): Mycorrhizal response in wheat cultivars: Relationship to phosphorus. - Canadian Journal of Botany 74: 19-25.

[23] Irannejad, H. (1991): Increase the quality and quantity of food corn product. - Zytoon Magazines 104: 16-19 (in Farsi).

[24] Jones, H. G. (1980): Interaction and integration of adaptive response to water stress. Royal Science Society of London, Series B 273: 193-205.

[25] Jahan, M., Koocheki, A., Nassiri Mahallati, M. (2007): The effects of arbuscular mycorrhizal fungus and free living nitrogen fixing bacteria on growth, photosynthesis and yield of corn (Zea mays L.) in conventional and ecological cropping systems. - Iranian Journal of Field Crops Research 5: 53-67 (in Persian with English summary).

[26] Kafi, M., Zand, E., Kamkar, B., Mahdavi-Damghani, A., Abbasi, F. (2010): Plant Physiology 2. - Jihad-e- Daneshgahi of Mashhad Press, Mashad (in Farsi)

[27] Kapoor, R., Giri, B., Mukerji, K. G. (2004): Improved growth and essential oil yield and quality in (Foeniculum vulgare Mill.) on mycorrhiza inoculation supplemented with Pfertilizer. - Bioresource Technology 93: 307-311.

[28] Kothari, S. K., Marschner, H., Romheld, V. (1991): Contribution of the VA mycorrhizal hyphae in acquisition of phosphorus and zinc by maize grown in a calcareous soil. - Plant and Soil 131: 177-185.

[29] Kramer, P. J., Boyer, J. S. (1995): Water Relations of Plants and Soils. - Academic Press, London.

[30] Li, X., George, E., Marschner, H. (1991): Extension of the phosphorus depletion zone in VA-mycorrhizal white clover in a calcareous soil. - Plant and Soil 136: 41-48.

[31] Logan, T. J., Goins, L. E., Jlindsay, B. (1997): Field assessment of trace element uptake by six vegetables from N-viro soil. - Water Environmental Research 69: 28-33.

[32] Marschner, H., Dell, B. (1994): Nutrient Uptake in Mycorrhizal Symbiosis. - In: Robson, A. D., Abbott, L. K., Malacjzuk, N. (eds.) Management of Mycorrhiza in Agriculture, Horticulture and Forestry. Kluwer Academic, Dordrecht.

[33] Mensah, J. K., Obadoni, B. O., Eruotor, P. G., Onome-Irieguna, F. (2006): Simulated flooding and drought effects on germination, growth, and yield parameters of sesame (Sesamum indicum L.). - African Journal of Biotechnology 5(13): 1249-1253.

[34] Misra, A., Sricastatva, N. K. (2000): Influence of water stress on Japanese mint. - Journal Herbs Spices Medician Plants 7: 51-58.

[35] Moradi-Dalini, A. 2012. Determination of reference crop evapotranspiration using lysimeter measurements and comparison with calculating by climate methods in Haji Abad Climate. - Final Report of Reseach Project, No. 1807. Hormozgan Agricultural and Natural Resources Research and Education Center, Agricultural Research, Education and Extension Organization (AREEO), Bandar Abbas, Iran.

[36] Munns, R., James, R. (2003): Screening methods for salinity tolerance. A case study with tetraploid wheat. - Plant and Soil 253: 201-218.

[37] Nasri, M., Khalatbari, M., Zahedi, W., Paknejad, F., Tohidimoghadam, H. R. (2008): Evaluation of macro and micro elements in drought stress condition in cultivars of rapeseed (Brassica napus L.). - American Journal of Agricultural and Biological Sciences 3(3): 579-583.

[38] Roldan-Fagardo, B. E., Barea, J. M., Ocampo, J. A., Azcon-Aguilar, C. (1982): The effect of season on VA mycorrhiza of the almond tree and of phosphate fertilization and species of endophyte on its mycorrhizal dependency. - Plant and Soil 68: 361-367.

[39] Ruiz-Lozano, J. M., Azcon, R. (1996): Mycorrhizal colonization and drought stress as factors affecting nitrate reductase activity in lettuce plants. - Agriculture, Ecosystems and Environment 60(2-3): 175-181. 
[40] Premachandra, G. S., Saneoka, H., Fujita,K., Ogata, S. (2002): Water stress. - Journal of Experimental Botany 43: 1451-1456.

[41] Sabannavar, S. J., Lakshman, H. C. (2009): Effect of Rock Phosphate solubilization using mycorrhizal fungi and phosphobacteria on two high yielding varieties of sesamum (Sesamum indicum L.). - World Journal of Agricultural Sciences 5(4): 470-479.

[42] Sanchez-Blanco, J., Fernandez, T., Morales, A., Morte, A., Alarcon, J. J. (2006): Variation in water stress, gas exchange and growth in Rosmarinus officinalis plants infected with Glamus deserticola under drought conditions. - Journal of Plant Physiology 161: 675-682.

[43] Saneoka, H., Moghaieb, R. E. A., Premachandra, G. S., Fujita, K. (2004): Nitrogen nutrition and water stress effects on cell membrane stability and leaf water relations in Agrostis palustris. - Environmental Expert Botany 52: 131-138.

[44] Schutz, M., Fangmeir, E. (2001): Growth and yield responses of spring wheat to elevated $\mathrm{CO}_{2}$ and water limitation. - Environmental Pollution 114: 187-194.

[45] Singh, D. K., Sale, P. W. G. (1997): Phosphorus supply and growth of frequently defoliated white Clover (Trifolium repense L.) in dry soil. - Journal of Plant Soil 205: 155-162.

[46] Smith, S. E., Read, D. J. (1997): Mycorrhizal Symbiosis. - Acadamic Press, London.

[47] Subramanian, K. S., Santhana-krishnan, P., Balasubramanian, P. (2006): Responses of field grown tomato plants to arbuscular mycorrhizal fungal colonization under varying intensities of drought stress. - Scientia Horticulturea 107(3): 245-253.

[48] Taiz, L., Ezeiger, H. (1998): Plant Physiology (2nd ed.). - Sinaye Associates Inc., Sonderland, MA.

[49] Tisdall, J. M. (1991): Fungal hyphae and structural stability of soil. - Australian Journal of Soil Research 29(6): 729-743.

[50] Vidal, I., Longeri, L., Hétier, J. M. (1999): Nitrogen uptake and chlorophyll meter measurements in spring wheat. - Nutr. Cycl. Agroecosyst 55: 1-6.

[51] Zhang, M., Duan, L., Tian, X., He, Z., Li, J., Wang, B., Li, Z. (2006): Unicanazoleinduced tolerance of Soybean to water deficit stress in relation to changes in photosynthesis, hormones and antioxidant system. - Journal of Plant Physiology 164: 709-717.

[52] Ziedan, E. S. H., Elewa, I. S., Mostafa, M. S., Sahab, A. F. (2011): Application of mycorrhizae for controlling root diseases of sesame. - Journal of Plant Protection Research 51(4): 55-61. 